\title{
Gum arabic microcapsules as protectors of the photoinduced degradation of riboflavin in whole milk
}

\author{
María L. Boiero, ${ }^{*}$ Mara Mandrioli,† Noelia Vanden Braber,† María T. Rodriguez-Estrada,† Norman A. García,§ \\ Claudio D. Borsarelli,\# and Mariana A. Montenegro* $\ddagger^{1}$ \\ *Departamento de Química, Universidad Tecnológica Nacional - Facultad Regional Villa María, Av. Universidad 450, Villa María, 5900 Córdoba, \\ Argentina \\ †Departamento de Ciencias de Alimentos, Alma-Mater Studiorum, Università di Bologna, 40127, Bologna, Italy \\ ‡Institutode Ciencias Básicas y Aplicadas, Universidad Nacional de Villa María, Villa María, 5900 Córdoba, Argentina \\ §Departamento de Química, Universidad Nacional de Río Cuarto, Río Cuarto, 5800 Córdoba, Argentina \\ \#Centro de Investigaciones y Transferencia de Santiago del Estero (CITSE-CONICET), Universidad Nacional de Santiago del Estero, \\ 4200 Santiago del Estero, Argentina
}

\section{ABSTRACT}

Microcapsules (MC) made with gum arabic (GA) as shell material without and with $\beta$-carotene $(\beta c)$ as core material were prepared by the spray-drying technique. The effect of these MC on the photodegradation of riboflavin (Rf) in whole milk by fluorescent daylight lamp irradiation was evaluated at a storage temperature of $4^{\circ} \mathrm{C}$. The additions of $1.37 \mathrm{mg} / \mathrm{mL}$ of $\mathrm{MC}$ without $\beta \mathrm{c}$ (MC-GA) and with $0.54 \mu \mathrm{g} / \mathrm{mL}$ of $\beta \mathrm{c}$ (MC- $\beta c-G A)$ decreased the apparent first-order rate constant of Rf photodegradation by approximately 26 and $30 \%$, respectively. A systematic kinetic and mechanistic analysis of the results indicates that the global protective effect of the MC is mainly due to the combination of quenching of the electronically excited triplet state of $\mathrm{Rf}$ and scavenging of the photogenerated reactive oxygen species, such as singlet molecular oxygen, superoxide radical anion and hydroxyl radical. A minor contribution to the photoprotective effect can be also associated with the inner-filter effect exerted by the $\mathrm{MC}$, which partially blocks the direct excitation of Rf. These results allow us to conclude that photodegradation of $\mathrm{Rf}$ in milk can be considerably reduced by the addition of small amounts of MC, avoiding large losses in the nutritional value of milk.

Key words: riboflavin photodegradation, $\beta$-carotene, gum arabic, reactive oxygen species

\section{INTRODUCTION}

The oxidative stability of milk and its products is of great importance for the dairy industry. It is well known that some of the photoinduced degradation process in milk occurs mainly because of the presence of vitamin

Received December 30, 2013.

Accepted May 1, 2014.

${ }^{1}$ Corresponding author: mamontenegro03@yahoo.com.ar
$\mathrm{B}_{2}$ [riboflavin (Rf)], which acts as a photosensitizer, absorbing environmental light to generate electronically excited states of the flavin, in particular the triplet excited state ( ${ }^{3} \mathbf{R f}^{*}$; Montenegro et al., 2007). In the presence of triplet molecular oxygen $\left({ }^{3} \mathrm{O}_{2}\right)$ or electron donors, or both, the ${ }^{3} \mathrm{Rf}^{*}$ is able to generate several reactive oxygen species (ROS), such as superoxide anion radical $\left(\mathrm{O}_{2}^{\bullet-}\right)$, hydroxyl radical $\left(\mathrm{HO}^{\bullet}\right)$, and singlet molecular oxygen $\left({ }^{1} \mathrm{O}_{2}\right)$ either by electrotransfer (type I mechanism) or energy-transfer (type II mechanism) reactions (Massad et al., 2004; Skibsted, 2010). These photogenerated ROS have a deleterious effect in milk, as they have a large degree of reactivity and may cause oxidation of proteins, vitamins, and lipids, with the collateral production of low-molecular-weight volatile compounds, responsible for off-flavor and nutritional quality loss in milk (Bradley, 1980; Mortensen et al., 2003; Mestdagh et al., 2011). In turn, the oxidative stability of milk depends on a delicate balance between the anti- and prooxidants processes (Halliwell and Gutteridge, 1999), which are influenced by several factors, such as the unsaturation degree of FA, content of transition metals, and antioxidant molecules (AOx; Kristensen et al., 2004). Adding AOx to scavenge harmful ROS species or molecules with the capability of quenching ${ }^{3} \mathrm{Rf}^{*}$, avoiding the formation of ROS, seem to be suitable strategies to avoid the undesired photoinduced off-flavor of milk.

Currently, natural AOx are preferred to synthetic ones to be added to milk to avoid or lessen toxicological side effects. Among these types of molecules, the lipid-soluble carotenoids (CAR) show exceptional nutritional and health-promoting properties, such as provitamin A activity and scavenging activity against ROS, in particular very efficient quenching of ${ }^{1} \mathrm{O}_{2}$, promoting the prevention and (or) reduction of human diseases associated with oxidative stress (Burton and Ingold, 1984; Liebler, 1993). 
However, the highly nonpolar properties of CAR preclude their direct utilization in aqueous media, where they aggregate and precipitate with the complete loss of their antioxidant properties. Among the several approaches for CAR vehiculization and controlled delivery in aqueous food matrices, spray-dried microencapsulation with edible biopolymers as coating material is a suitable and economical feasible method (RodriguezHuezo et al., 2004; Barbosa et al., 2005; Gharsallaoui et al., 2007). In this process, the biopolymer wall acts as a physical permeable barrier to diffusion of oxygen and other molecules (Edge et al., 1997; Bustos et al., 2003) and allows the stabilization, transport, and controlled delivery of CAR into the aqueous media (RodríguezHuezo et al., 2004; Barbosa et al., 2005).

In a previous study, we evaluated the effect of lycopene microencapsulation by spray drying with a gum arabic (GA)-sucrose (8:2) mixture in the Rf-mediated photosensitized degradation of vitamins $\mathrm{A}$ and $\mathrm{D}_{3}$ in skim milk, using white fluorescence lamps as a light source, as the visible absorption band of Rf overlaps with the blue-shifted emission of the fluorescent light (Montenegro et al., 2007). The results indicated that the addition of $6.5 \mathrm{mg} / \mathrm{mL}$ of this microencapsulated skim milk produced a reduction of approximately $45 \%$ of the photosensitized degradation rate of both vitamins.

In a more recent study, we evaluated the ${ }^{1} \mathrm{O}_{2}$-quenching capacity of microcapsules (MC) of GA (MC-GA) or maltodextrin containing natural AOx molecules such as CAR or tocopherol derivatives (Faria et al., 2010). The results indicated that the ${ }^{1} \mathrm{O}_{2}$-quenching efficiency by the $\mathrm{AOx}$ in $\mathrm{MC}$ was strongly dependent on the lipophilicity degree of the AOx, being more efficient in the polar ones due to compartmentalization effects of the $\mathrm{AOx}$ in the core of the MC that modified the accessibility of ${ }^{1} \mathrm{O}_{2}$. Additionally, it was demonstrated that empty MC of GA were efficient quenchers of ${ }^{1} \mathrm{O}_{2}$, due to the interaction with amino acid residues (Trp, His, and Met, among others) of the protein moiety present in this glycoprotein (Mahendran et al., 2008). Later, for the same series of microencapsulated AOx studied before, Rodrigues et al. (2012) analyzed the antioxidant activity against both reactive oxygen and nitrogen species, such as peroxyl radical $\left(\mathrm{ROO}^{\bullet}\right)$, hydrogen peroxide $\left(\mathrm{H}_{2} \mathrm{O}_{2}\right), \mathrm{HO}^{\bullet}$, and peroxynitrite anion $\left(\mathrm{ONOO}^{-}\right)$. They found that the scavenging capacities were influenced by the wall material and by the type of antioxidant molecule, being in all cases higher for the microcapsules with GA than with maltodextrin.

Due to the relevance of Rf photochemistry in milk, the objective of this work was the evaluation of the efficiency of MC-GA itself and of MC-GA containing the provitamin A precursor $\beta$-carotene $(\boldsymbol{\beta c})$ as scavengers of ROS generated by fluorescent light photosensitization of Rf in whole milk.

\section{MATERIALS AND METHODS}

\section{Materials and Chemicals}

$\beta$-Carotene (98\% purity), Rf ( $\geq 98 \%)$, sodium azide $\left(\mathbf{N a N}_{3}\right)$, superoxide dismutase (SOD), nitro blue tetrazolium (NBT), 2-deoxy-D-ribose, 6-hydroxy-2,5,7,8tetramethylchroman-2-carboxylic acid [Trolox (TX); 99.5\% purity], and SDS were supplied by Sigma-Aldrich (St. Louis, MO). Food-grade GA (molecular weight = $3.5 \times 10^{5} \mathrm{~g} / \mathrm{mol}$ ) was purchased from Colloides Naturels Brasil (São Paulo, Brazil). Acetate buffer was from Merck Química Argentina S.a.i.c. (Buenos Aires, Argentina); $\mathrm{FeCl}_{3}, \mathrm{H}_{2} \mathrm{O}_{2}, \mathrm{KH}_{2} \mathrm{PO}_{4}, \mathrm{~K}_{2} \mathrm{HPO}_{4}$, ascorbic acid, thiobarbituric acid (TBA), TCA, hydroxylamine hydrochloride (HAHC), all analytical grade, were obtained from Biopack Productos Químicos (Buenos Aires, Argentina); and HPLC-grade solvents: methanol, hexane, 1-butanol, ultrapure water, and glacial acetic acid were from Merck KGaA (Darmstadt, Germany; LiChrosolv). The milk samples were prepared from wholemilk powder of a recognized Argentinean trademark.

\section{Preparation of MC}

The MC were prepared with GA as shell material (MC-GA) and with $\beta$-carotene (MC- $\beta$ c-GA) by using a laboratory-scale spray-dryer system (Labplant SD-04; Labplant UK Ltd., Huddersfield, 123 UK), under the following working conditions: aspersion nozzle diameter of $0.7 \mathrm{~mm}$, air pressure of $5 \mathrm{kgf} / \mathrm{cm}^{2}$, and air flow rate of $30 \mathrm{~mL} / \mathrm{min}$, entrance and exit air temperatures of 170 and $110^{\circ} \mathrm{C}$, respectively. Gum arabic solutions [30\% (wt/vol) of soluble solid] were prepared in water at $45^{\circ} \mathrm{C}$ and kept under continuous stirring until the temperature reached $30^{\circ} \mathrm{C}$. $\beta$-Carotene was dissolved in dichloromethane and a small aliquot was added to the GA aqueous solution. The mixture was stirred at 7,000 rpm for 30 min to obtain an emulsion. Afterward, the emulsion was diluted with water to obtain a $20 \%$ (wt/vol) GA solution. The emulsion was placed in the spray-dryer chamber, maintaining slow agitation during the spray-drying process. The microcapsules obtained were immediately stored in a glass bottle under $\mathrm{N}_{2}$ atmosphere at $-18^{\circ} \mathrm{C}$ to avoid $\beta \mathrm{c}$ degradation.

\section{Quenching of ${ }^{3} \mathrm{Rf}^{*}$ by $M C$ and Laser Flash Photolysis Experiments}

Generation and detection of ${ }^{3} \mathrm{Rf}^{*}$ were performed by laser flash photolysis (LFP) experiments using the third harmonic at $355 \mathrm{~nm}$ of a neodymium-doped yttrium alu- 
minum garnet (Nd:YAG) Minilite II laser with 7 ns of full width at half maximum (FWHM) from Continuum Inc. (Santa Clara, CA). Triplet-to-singlet difference transient absorption spectra of $\mathrm{Rf}(35 \mu M)$ in Ar-saturated phosphate buffer ( $\mathrm{pH}$ 7.4) solutions were recorded with the m-LFP 112 laser-flash photolysis apparatus from Luzchem Research Inc. (Ottawa, ON, Canada) linked to a 300-MHz Tektronix TDS 3032B digital oscilloscope (Tektronix Inc., Beaverton, OR) for signal acquisition, as described in Montenegro et al. (2007).

\section{Scavenging of Free Radical Species by MC in Buffer Solution}

Hydroxyl radicals $\left(\mathrm{HO}^{\bullet}\right)$ were generated via the Fenton reaction at $\mathrm{pH} 7.4$ (Aruoma, 1994). In the presence of deoxyribose, the $\mathrm{HO}^{\bullet}$ reacts, producing malondialdehyde (MDA) among other products, which formed a pinkish adduct in the presence of TBA, allowing its quantification by UV-visible spectroscopy (Gutteridge, 1981). The $\mathrm{HO}^{\bullet}$ scavenging effect of the $\mathrm{MC}$ was investigated as follows: the reaction was performed in $50 \mathrm{~m} M$ phosphate buffer ( $\mathrm{pH}$ 7.4) containing $10 \mathrm{mM}$ deoxyribose, $100 \mathrm{mM} \mathrm{H}_{2} \mathrm{O}_{2}, 1 \mathrm{mM} \mathrm{FeCl}{ }_{3}$, and $5 \mathrm{mM}$ EDTA in the presence and absence of the MC samples. The reaction started with the addition of ascorbic acid in a final concentration of $5 \mathrm{~m} M$. The reaction mixture was incubated for $1 \mathrm{~h}$ at $37^{\circ} \mathrm{C}$ in a water bath. Then, $1 \%$ (wt/vol) TBA and 2.8\% (wt/vol) cold TCA were added and heated to boiling temperature $\left(95-100^{\circ} \mathrm{C}\right)$ for 20 min to cause the colored adduct to form, of which the absorbance was measured at $532 \mathrm{~nm}$. Trolox was used as antioxidant reference.

The scavenging of anion superoxide $\mathrm{O}_{2}{ }^{--}$was determined according to the method described by Sabu and Kuttan (2002) using NBT as colorimetric reagent. The assay is based on the $\mathrm{O}_{2}{ }^{--}$generation by HAHC autoxidation, which reduces NBT to nitrite $\left(\mathrm{NBT}^{+\bullet}\right)$. In the presence of water, the organic radical-cation $\mathrm{NBT}^{+}$, produces the stable cation monoformazan $\left(\mathrm{MF}^{+}\right)$, which absorbs at $560 \mathrm{~nm}$. The competitive scavenging of $\mathrm{O}_{2}{ }^{\bullet-}$ by the MC was studied as follows: in a test tube, the desired $\mathrm{MC}$ concentration was weighed and dissolved in $150 \mathrm{~m} M$ sodium carbonate buffer ( $\mathrm{pH}$ 10) containing $1.8 \mathrm{~m} M$ NBT, $1 \mathrm{~m} M$ EDTA, and $6 \mathrm{~m} M$ HAHC. The samples were incubated for $1 \mathrm{~h}$ at $37^{\circ} \mathrm{C}$ and afterward, the absorbance of $\mathrm{MF}^{+}$was measured at $560 \mathrm{~nm}$. The enzyme SOD was used as antioxidant reference.

The percentage radical scavenging $(\mathbf{\%} \mathbf{S})$ by the $\mathrm{MC}$ was calculated using Equation 1:

$$
\% \mathrm{~S}=\left(1-\frac{A_{X}}{A_{0}}\right) \times 100,
$$

where $A_{0}$ is the absorbance of the control and $A_{X}$ is the absorbance in the presence of MC- $\beta c-G A, M C-G A$, or the reference compound. The results were expressed as Trolox equivalent antioxidant capacity (TEAC) for $\mathrm{HO}^{\bullet}$ and $\mathrm{SOD}$ equivalent antioxidant activity $\left(\mathbf{E A A} \mathbf{A}_{\text {SOD }}\right)$ for $\mathrm{O}_{2}{ }^{--}$according to the ratio between initial slopes of the $\% \mathrm{~S}$ graphs. The assays were performed in triplicate and the results are reported with the respective standard deviation. Absorbance measurements were performed using a 1-cm optical path quartz cuvette on an Analytik Jena Specord S600 diode array spectrophotometer (Analytik Jena AG, Jena, Germany) at room temperature.

\section{Milk Photooxidation}

A recognized Argentinean brand of whole-milk powder supplemented with iron (as slightly soluble ferric phosphate, of low bioavailability and possibility to catalyze oxidation reactions, leading to significant changes in the nutritional value of milk) and vitamin $\mathrm{C}$ was reconstituted with ultrapure water (resistivity $<18.2 \mathrm{M} \Omega \cdot \mathrm{cm}$ at $25^{\circ} \mathrm{C}$ ) according to the manufacturer's indications. The milk photodegradation was performed by placing $500-\mathrm{mL}$ aliquots in glass bottles (cutoff of $310 \mathrm{~nm}$ ), which were stored at shelf temperature $\left(4^{\circ} \mathrm{C}\right)$ under 1,000-lx fluorescent lamps for $120 \mathrm{~h}$. Milk aliquots were randomly sampled at different times for $\mathrm{Rf}$ determination. A control was also performed in darkness under the same conditions. The photodegradation assay was divided into 2 protocols called Kinetic I and Kinetic II, respectively, where Kinetic I was performed with the addition of $1.37 \mathrm{mg} / \mathrm{mL}$ of MC-GA to milk and Kinetic II with the addition of $1.37 \mathrm{mg} / \mathrm{mL}$ of MC$\beta c-G A$ to milk. Details of each protocol procedure are given in the following section.

\section{Protocols for HPLC Quantification of Rf in Milk}

Kinetic I. The sample preparation consisted in a hot acid extraction based on the method of the Association of Official Analytical Chemists (AOAC, 1984; method 970.65). Briefly, $5 \mathrm{~mL}$ of milk sample was treated with $5 \mathrm{~mL}$ of $0.1 \mathrm{M} \mathrm{HCl}$ and autoclaved at $121^{\circ} \mathrm{C}$ for $30 \mathrm{~min}$. Later, the pH was adjusted to 4.5 with $1.25 \mathrm{M}$ sodium acetate and the final volume of $25 \mathrm{~mL}$ was reached by addition of sodium $0.2 M$ acetate buffer. The samples were filtered through $0.45-\mu \mathrm{m}$ membrane filters before being injected into the HP1050 series HPLC apparatus (Agilent Technologies Inc., Palo Alto, CA) equipped with an analytical Phenomenex Synergi RP80A Fusion $4 \mathrm{U} \mathrm{C}_{18}$ column $(150 \times 3.0 \mathrm{~mm}$; Phenomenex Inc., Torrance, CA) with a precolumn. The signals were recorded with a fluorescence detector operated at an excitation 
wavelength of $453 \mathrm{~nm}$ and emission wavelength of 580 $\mathrm{nm}$. The mobile phase used was a mixture of water, methanol, and glacial acetic acid (ratio of 65:35:0.1) at a flow rate of $0.8 \mathrm{~mL} / \mathrm{min}$. This procedure was carried out in duplicate for each sample.

An external calibration curve with authentic Rf was performed with a concentration range of 0.1 to $3.0 \mu \mathrm{g} /$ $\mathrm{mL}$. Linear regression equations and correlation coefficients were calculated $\left(\mathrm{y}=36.85261 \mathrm{x}+1.03471 ; \mathrm{R}^{2}\right.$ $=0.99 ; \mathrm{n}=8)$ and 2 independent replicates were performed per concentration.

Kinetic II. To overcome the HPLC partial overlapping of matrix interferences with Rf, a different extraction method of Rf was used, which was based on the solid-phase extraction method described by Ashoor et al. (1985). We used a $\mathrm{C}_{18}$ extraction cartridge (SepPack; Agilent Technologies Inc.). A mixture of $0.02 M$ sodium acetate buffer at $\mathrm{pH} 4.0$ and methanol (1:1, vol/ vol) was used as the eluent solution. The sample was subsequently concentrated on a rotary evaporator and filtered with a $0.45-\mu \mathrm{m}$ membrane filter before injecting into the HPLC equipment. The chromatographic analysis was performed under identical conditions used in the Kinetic I protocol, except for the use of 1 diode array detector at $270 \mathrm{~nm}$. This procedure was carried out in duplicate for each sample. The Rf was quantified by using an external standard calibration curve, following the same concentration range and procedure as previously described for Kinetics I. Linear regression equations and correlation coefficients were calculated $\left(\mathrm{y}=30.723 \mathrm{x}+0.9668 ; \mathrm{R}^{2}=0.98 ; \mathrm{n}=8\right)$.

The level of Rf found in milk, by both protocols, before light exposure is in agreement with data reported in the literature (e.g., $0.8-3.0 \mu \mathrm{g} / \mathrm{mL}$; Muñoz et al., 1994).

\section{Determination of the Rf Photooxidative Mechanism in Milk}

Riboflavin-mediated photosensitized generation of ${ }^{1} \mathrm{O}_{2}$ and $\mathrm{O}_{2}{ }^{--}$and the self-degradation of $\mathrm{Rf}$ in milk were evaluated by analysis of the degradation rate of $\mathrm{Rf}$ in the absence and presence of a specific quencher or scavenger for each ROS, such as $\mathrm{NaN}_{3}(1 \mathrm{mM})$ for ${ }^{1} \mathrm{O}_{2}$ (Wilkinson et al., 1995) or $\operatorname{SOD}(5 \mu \mathrm{g} / \mathrm{mL})$ for $\mathrm{O}_{2}{ }^{--}$(Criado et al., 1996). The remaining $\mathrm{Rf}$ concentration was determined as a function of the irradiation time with the same protocol described for Kinetic I (see above).

\section{Statistical Analysis}

The experimental data were processed and analyzed with OriginPro 8 software (OriginLab Software Corp.,
Northampton, MA) for kinetic analysis. The experiments were done in duplicate ( $\mathrm{Rf}$ photooxidation assays) and triplicate (ROS scavenging and ${ }^{3} \mathrm{Rf}^{*}$-quenching assays) and subjected to statistical ANOVA (one-way ANOVA) with a significance level of $P<0.05$. These calculations were performed using the Statgraphics Centurion XV program (StatPoint Technologies Inc., Warrenton, VA). Data were presented as mean value \pm standard deviation.

\section{RESULTS AND DISCUSSION}

\section{Photoprotection of Rf in Milk by MC-GA}

Figure 1 shows the degradation kinetics of Rf determined by HPLC (see the Protocols for HPLC Quantification of Rf in Milk section) in whole milk stored in dark and light conditions at $4^{\circ} \mathrm{C}$, without and with the addition of $1.37 \mathrm{mg} / \mathrm{mL}$ of MC-GA and MC- $\beta c-G A$. Under dark conditions, the flavin was not degraded during the observed time range, whereas under illumination with fluorescent light, Rf was consumed following first-order kinetics, according to the equation [Rf] $=[\mathrm{Rf}]_{0} \times \exp \left(-k_{\mathrm{pd}} t\right)$, where $\boldsymbol{k}_{\mathrm{pd}}$ represents the global first-order rate constant of $\mathrm{Rf}$ photodegradation and $t$ is the storage time (Table 1 ).

As compared with the milk samples without additive, the presence of MC significantly reduced the photodegradation of the flavin, and the photoprotection percentage of $\mathrm{Rf}\left(\mathbf{\%} \mathbf{P} \mathbf{P}_{\mathrm{Rf}}\right)$ can be calculated using Equation 2:

$$
\% \mathrm{PP}_{\mathrm{Rf}}=\left(1-\frac{k_{\mathrm{pd}}^{\mathrm{MC}}}{k_{\mathrm{pd}}{ }^{0}}\right) \times 100,
$$

where $k_{\mathrm{pd}}{ }^{0}$ and $k_{\mathrm{pd}}{ }^{\mathrm{MC}}$ are the photodegradation rate constants of $\mathrm{Rf}$ in the absence and presence of $\mathrm{MC}$ in milk, respectively. In the present case, the addition of $1.37 \mathrm{mg} / \mathrm{mL}$ of $\mathrm{MC}$ produced a $\% \mathrm{PP}_{\mathrm{Rf}}$ of $26( \pm 4)$ and $30 \%( \pm 5 \%)$ for MC-GA and MC- $\beta c-G A$, respectively. Under the studied conditions, the presence of $0.54 \mu \mathrm{g}$ of $\beta c / m L$ produced a slight increment in the photoprotection of Rf.

It is well established that photosensitization of $\mathrm{Rf}$ in milk samples generates ROS as singlet molecular oxygen $\left({ }^{1} \mathrm{O}_{2}\right)$ and anion superoxide $\left(\mathrm{O}_{2}{ }^{--}\right)$. To explore the participation degree of different photogenerated ROS in the degradation of $\mathrm{Rf}$ in milk, degradation kinetics of the flavin were analyzed by HPLC in the presence of specific deactivators of ROS, such as $\mathrm{NaN}_{3}$ for ${ }^{1} \mathrm{O}_{2}$ and SOD for $\mathrm{O}_{2}{ }^{\bullet-}$, respectively (Serrano et al., 2013).

Figure 2 shows the effect on the first-order kinetics of Rf photodegradation of the addition of $1 \mathrm{mM} \mathrm{NaN}{ }_{3}$ or 5 $\mu \mathrm{g} / \mathrm{mL} \mathrm{SOD}$, which are concentrations large enough to 
produce almost total deactivation or scavenging of both ROS. Therefore, by comparing the observed first-order rate constants of $\mathrm{Rf}\left(k_{\mathrm{pd}}\right)$ without and with $\mathrm{NaN}_{3}$ or $\mathrm{SOD}$, the reduction of $k_{\mathrm{pd}}$ was observed in the presence of both additives, resulting in the calculation of $\% \mathrm{PP}_{\mathrm{Rf}}$ $=71$ and $17 \%$ for $\mathrm{NaN}_{3}$ and $\mathrm{SOD}$, respectively, indicating that the main $\mathrm{Rf}$ degradation pathway is caused by reaction with ${ }^{1} \mathrm{O}_{2}$. The remaining $12 \%$ can be caused by additional degradation mechanisms of Rf, which could involve other ROS, such as $\mathrm{HO}^{\bullet}$ or $\mathrm{H}_{2} \mathrm{O}_{2}$. These species
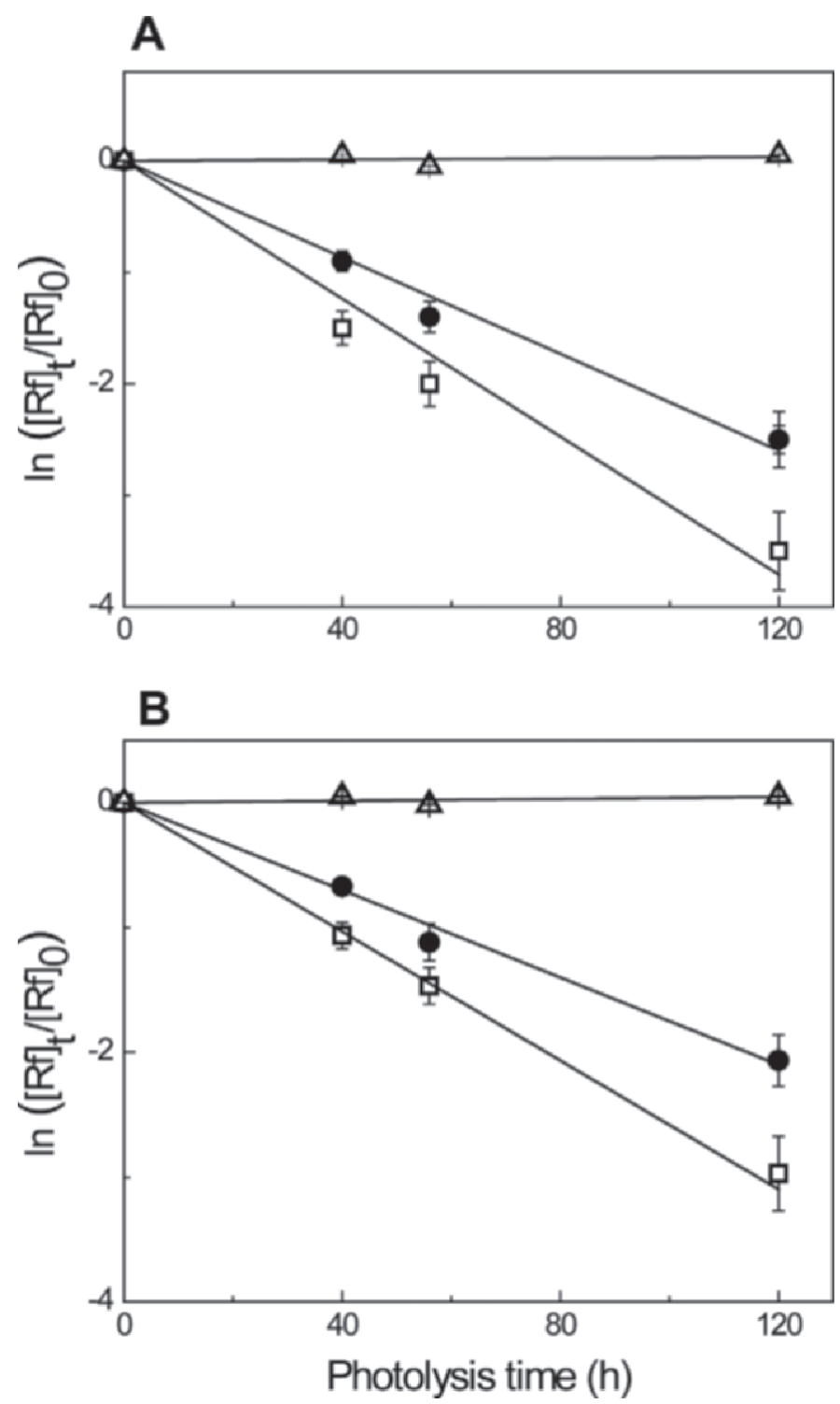

Figure 1. Riboflavin (Rf) degradation kinetics in reconstituted powdered whole milk stored at $4^{\circ} \mathrm{C}$ under light and dark conditions, obtained from HPLC analysis. (A) With addition of $1.37 \mathrm{mg} / \mathrm{mL}$ of microcapsules (MC) of gum arabic (MC-GA); (B) with addition of $1.37 \mathrm{mg} / \mathrm{mL}$ of MC-GA with $\beta$-carotene $(\mathrm{MC}-\beta \mathrm{c}-\mathrm{GA}) . \mathrm{t}=$ storage time; $\square=$ milk + light; $\bullet=$ milk $+\mathrm{MC}+$ light; $\Delta=$ milk in the dark. Error bars represent the SD calculated in duplicate experiments.
Table 1. Global first-order rate constant of riboflavin (Rf) photodegradation $\left(k_{\mathrm{pd}}\right)$ in whole milk without and with addition of $1.37 \mathrm{mg} / \mathrm{mL}$ of microcapsules (MC) of gum arabic (MC-GA) and MCGA with $\beta$-carotene $(\mathrm{MC}-\beta \mathrm{c}-\mathrm{GA})$ at $4^{\circ} \mathrm{C}$

\begin{tabular}{lcc}
\hline Sample & $\begin{array}{c}k_{\text {pd }} / 10^{-3}\left(\mathrm{~h}^{-1}\right) \\
\text { with MC-GA }\end{array}$ & $\begin{array}{c}k_{\text {pd }} / 10^{-3}\left(\mathrm{~h}^{-1}\right) \\
\text { with MC- } \beta \mathrm{c}-\mathrm{GA}\end{array}$ \\
\hline Milk + light & $30 \pm 5$ & $25 \pm 4$ \\
Milk + MC + light & $22 \pm 2$ & $18 \pm 6$ \\
Milk in the dark & $0.3 \pm 0.1$ & $0.2 \pm 0.1$ \\
\hline
\end{tabular}

can be generated in milk either by microbial metabolism $\left(\mathrm{H}_{2} \mathrm{O}_{2}\right)$ or by Fenton reaction for $\mathrm{HO}^{\bullet}$ (Ito et al., 2003). In particular, in our experiments, the generation of $\mathrm{HO}^{\bullet}$ via the Fenton reaction was favored, as the milk sample was commercially fortified with ferric phosphate as iron source, and with vitamin $\mathrm{C}$, which can act as a catalyst for the Fenton reaction.

The possibility of an additional photoprotection mechanism by inner filter effect by the $\mathrm{MC}$ in the region where Rf absorbs ambient light (380-500 nm) can be ruled out because in a previous study (Montenegro et al., 2007), we demonstrated by diffuse reflectance measurements that skim milk with $6.5 \mathrm{mg} / \mathrm{mL}$ of MCGA containing lycopene only contributed $<2 \%$ of the photoprotection. In the present case, a lesser concentration of MC was used and, therefore, the inner-filter effect was expected to be negligible.

In addition to evaluating the photodegradation of $\mathrm{Rf}$ in milk as the result of the combination of several

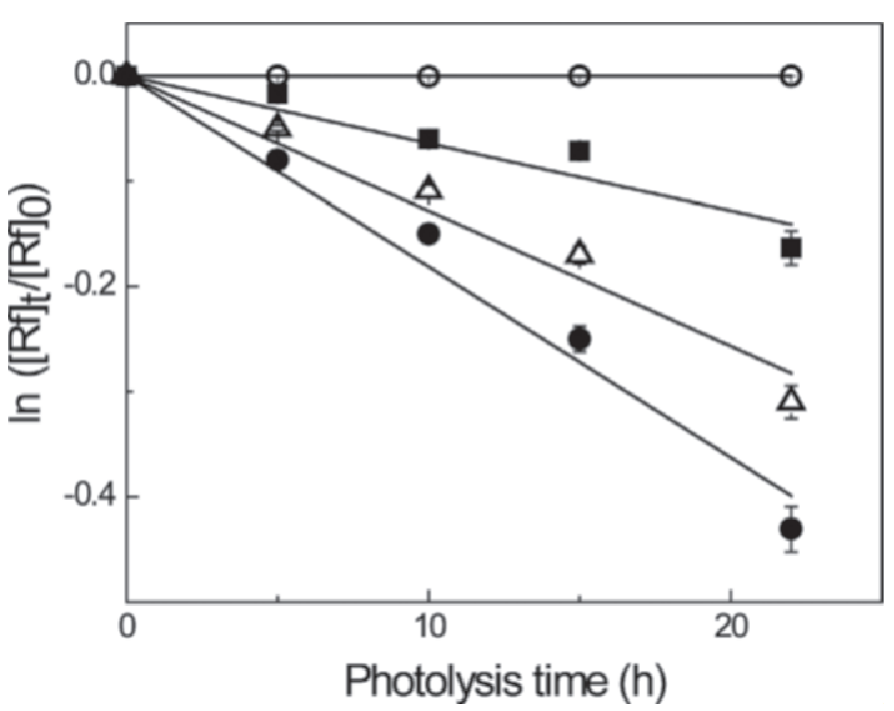

Figure 2. Riboflavin (Rf) degradation kinetics in milk samples with and without addition of $0.1 \mathrm{M}$ sodium azide $\left(\mathrm{NaN}_{3}\right)$ and $0.5 \mathrm{mg} /$ $\mathrm{mL}$ superoxide dismutase (SOD), stored under conditions of light and dark at $4^{\circ} \mathrm{C}$, obtained by HPLC measurements. $\mathrm{t}=$ storage time; $\mathrm{O}$ $=$ milk in the dark (negative control); $\bullet=$ milk + light (positive control); $\Delta=$ milk + SOD; $=$ milk $+\mathrm{NaN}_{3}$. Error bars represent the $\mathrm{SD}$ calculated in duplicate experiments. 
ROS in different proportions, we evaluated the specific photoprotective effect of both spray-dried MC-GA and MC- $\beta$ c-GA preparations toward the ${ }^{3} \mathrm{Rf}^{*}$ and ROS in aqueous phosphate buffer solutions, as described in the following sections.

\section{Quenching of ${ }^{3} R f^{*}$ by $G A$ and MC-GA in Buffer Solutions}

In previous work, we demonstrated that ${ }^{3} \mathrm{Rf}^{*}$ was almost not quenched by lycopene in $30 \mathrm{~m} M$ Triton $\mathrm{X}-100$ aqueous micelle solutions (Montenegro et al., 2007). Similar results were obtained by Cardoso et al. (2007), who studied the deactivation of ${ }^{3} \mathrm{Rf} *$ by ascorbate, CAR, and tocopherols in aqueous food model systems, demonstrating that $\beta c$, lycopene, and crocin were not able to quench ${ }^{3} \mathrm{Rf}^{*}$. Therefore, in the present work, only the interaction of ${ }^{3} \mathrm{Rf}^{*}$ with GA was analyzed by laser flash photolysis. Direct evidence of ${ }^{3} \mathrm{Rf}^{*}$ quenching by $\mathrm{GA}$ in $\mathrm{N}_{2}$-saturated phosphate buffer solutions was obtained by monitoring the typical transient absorption of ${ }^{3} \mathrm{Rf}^{*}$ at $720 \mathrm{~nm}$ after laser excitation at 355 $\mathrm{nm}$, using transient absorption spectroscopy (Figure 3).

We evaluated the increases in the decay rate $k_{\mathrm{T}}(=1 /$ $\tau_{\mathrm{T}}$ ), where $\tau_{\mathrm{T}}$ is the lifetime of the triplet state, of the ${ }^{3} \mathrm{Rf}^{*}$ monitored at $710 \mathrm{~nm}$ as the GA concentration was increased (Equation 3), where $k_{\mathrm{T}}^{0}=\left(\tau_{\mathrm{T}}^{0}\right)^{-1}=(27 \mu \mathrm{s})^{-1}$ is the decay rate of the triplet state in the absence of GA, and ${ }^{3} k_{\mathrm{Q}}{ }^{\mathrm{GA}}$ is the bimolecular quenching rate constant of ${ }^{3} \mathrm{Rf}^{*}$ by GA:

$$
k_{\mathrm{T}}=k_{\mathrm{T}}^{0}+{ }^{3} k_{\mathrm{Q}}^{\mathrm{GA}}[\mathrm{GA}]
$$

The inset of Figure 3 shows a linear dependency of Equation 3, allowing the calculation of ${ }^{3} k_{\mathrm{Q}}^{\mathrm{GA}}=1.6$ $( \pm 0.3) \times 10^{9} \mathrm{M}^{-1} \mathrm{~s}^{-1}$. Therefore, GA is able to quench ${ }^{3} \mathrm{Rf}^{*}$ with almost a diffusion-controlled quenching rate, in a similar fashion to the quenching of ${ }^{3} \mathrm{Rf}^{*}$ by free amino acids, such as His and Tyr [e.g., ${ }^{3} k_{\mathrm{Q}}{ }^{\text {His }}=$ $3.8( \pm 0.5) \times 10^{8} M^{-1} \mathrm{~s}^{-1}$ and ${ }^{3} k_{\mathrm{Q}}{ }^{\text {Tyr }}=1.8( \pm 0.8) \times 10^{9}$ $M^{-1} \mathrm{~s}^{-1}$ ] as studied in this work (data not shown), in accordance with previous reported values (Cardoso et al., 2004; Huvaere and Skibsted, 2009). As GA is a heteropolysaccharide containing about $2 \%$ polypeptide (Mahendran et al., 2008), the quenching effect of ${ }^{3} \mathrm{Rf}^{*}$ by GA can be associated with the presence of amino acid residues, such as His and Tyr, in the protein moiety of GA. Assuming the same quenching efficiency of ${ }^{3} \mathrm{Rf}^{*}$ by GA forming MC, the shortening of the flavin triplet lifetime $(\sim 21 \mu \mathrm{s})$ by the addition of $1.37 \mathrm{mg} /$ $\mathrm{mL}$ MC-GA allows the calculation of the quenching fraction of ${ }^{3} \mathrm{Rf}^{*}\left(f_{\mathrm{T}}\right)$ by GA (i.e., $f_{\mathrm{T}}=1-\tau / \tau_{0}=0.2$ ), indicating that approximately $20 \%$ of the Rf photo- protection observed in the presence of MC-GA can be associated with the quenching of ${ }^{3} \mathrm{RF}^{*}$, which in turn, avoids in the similar extension the generation of ROS.

\section{Scavenging of $\mathrm{HO}^{\circ}$ and $\mathrm{O}_{2}^{--}$by the $\mathrm{MC}$ in Buffer Solution}

Figure 4 shows the $\% \mathrm{~S}$ of $\mathrm{HO}^{\bullet}$ and $\mathrm{O}_{2}{ }^{\bullet-}$ by $\mathrm{MC}$ and TX or SOD as reference AOx, respectively. It can be observed that at $\mathrm{MC}$ concentrations $(1.37 \mathrm{mg} / \mathrm{mL})$ used in the experiments of milk photooxidation, MCGA or MC- $\beta c-G A$ produce more efficient scavenging of $\mathrm{O}_{2}{ }^{--}$than of $\mathrm{HO}^{\circ}$. In this case, for the calculation of the TEAC and $\mathrm{EAA}_{\mathrm{SOD}}$ values, the experimental data of the plots of $\% \mathrm{~S}$ versus $[\mathrm{AOx}](M)$ was fitted with a second-order polynomial function, and the slopes of the initial linear region obtained for the $\mathrm{MC}$ were divided for those of TX or SOD, and the respective TEAC and EAA $_{\text {SOD }}$ were obtained (Table 2). The results show that MC- $\beta c-G A$ was an about 1.5 to 1.7 times more efficient scavenger than the "empty" MC-GA. This effect can be attributed to the scavenging ability of $\beta c$ as a consequence of the presence of an extended conjugated double bond system in its structure (Mortensen et al., 2001), which reduces the energy barrier for reaction with free radicals, such as $\mathrm{ROO}^{\circ}, \mathrm{OH}^{\bullet}$, and $\mathrm{O}_{2}{ }^{--}$. However, the data of Table 2 also indicates that the scavenger activity of MC-GA for both ROS is not negligible, in agreement with antioxidant effects attributed to GA (Al-Majed et al., 2003; Trommer and Neubert, 2005).

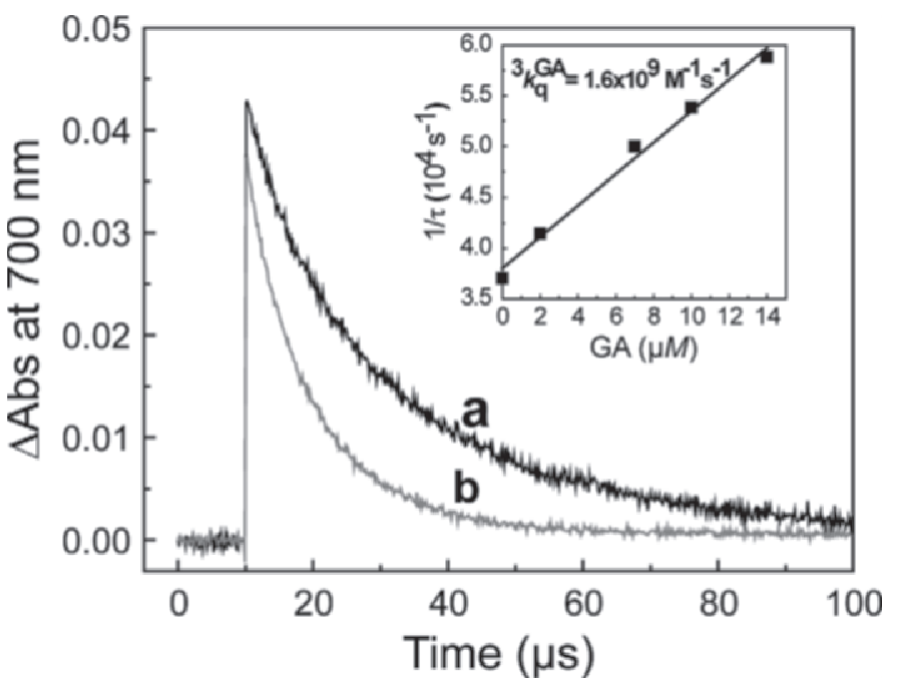

Figure 3. Transient absorption decay at $720 \mathrm{~nm}$ of the triplet excited state of riboflavin $\left({ }^{3} \mathrm{Rf}^{*}\right)$ after laser pulsed excitation at $355 \mathrm{~nm}$ of $\mathrm{Rf}$ in $\mathrm{N}_{2}$-saturated phosphate buffer solutions as a function of the gum arabic (GA) concentration: (a) $0 \mu M$; (b) $14 \mu M$. Inset: SternVolmer plot for the quenching of ${ }^{3} \mathrm{Rf}^{*}$ by GA (Equation 3 in the text). $\tau=$ lifetime of the triplet state; ${ }^{3} k_{\mathrm{Q}}{ }^{\mathrm{GA}}=$ biomolecular quenching rate constant of ${ }^{3} \mathrm{Rf}^{*}$ by GA. 


\section{Mechanistic Analysis of Photooxidation and Photoprotection in Milk}

Depending on the light exposition, presence of molecular oxygen $\left({ }^{3} \mathrm{O}_{2}\right)$, and concentration of dissolved substrates (Q), the $\mathrm{Rf}$ is capable of promoting the oxidation of various milk constituents through photosensitized ROS generation (Massad et al., 2004). In this process, the light absorption promotes the sensitizer (Rf, in ground state) to the electronically excited singlet and triplet states ${ }^{1} \mathrm{Rf}^{*}$ and ${ }^{3} \mathrm{Rf}^{*}$, respectively (steps 1 and 2 in Figure 5). In the presence of electron donor molecules (as $\mathrm{MC}$ ), the ${ }^{3} \mathrm{Rf}^{*}$ can be quenched by an electron-transfer process to yield radical species (step 3 in Figure 5; Heelis, 1982). In this work, we demonstrate that MC-GA is an efficient quencher of ${ }^{3} \mathrm{Rf}^{*}$; considering that GA concentration is the same in both microencapsulated (MC-GA and MC- $\beta \mathrm{c}-\mathrm{GA}$ ) and that $\beta c$ is not able to quench ${ }^{3} \mathrm{Rf}^{*}$, the fraction quenching of ${ }^{3} \mathrm{Rf}^{*}$ would be the same both cases.

Furthermore, in aerobic conditions, the ${ }^{3} \mathrm{Rf}^{*}$ is quenched by ground-state oxygen $\left({ }^{3} \mathrm{O}_{2}\right)$ through energy-transfer (type II mechanism) and electron-transfer (type I mechanism) reactions to produce singlet molecular oxygen ${ }^{1} \mathrm{O}_{2}$ (step 4 in Figure 5) or the superoxide radical anion species $\left(\mathrm{O}_{2}{ }^{--}\right.$; step 5 in Figure 5), respectively (Skibsted, 2010; Massad et al., 2004). In aqueous media, the capacity of ${ }^{3} \mathrm{Rf}^{*}$ to generate ${ }^{1} \mathrm{O}_{2}$ is 60 times greater than that of $\mathrm{O}_{2}{ }^{--}$, suggesting that the main ROS formed during milk light-induced oxidation is ${ }^{1} \mathrm{O}_{2}$. In turn, ${ }^{1} \mathrm{O}_{2}$ can interact with electron donor molecules (as MC) through physical or reactive processes, or both (steps 6 and 7 in Figure 5). In this context, taking into account the values of the total quenching rate constant of ${ }^{1} \mathrm{O}_{2}\left(k_{\mathrm{t}}\right)$ by MC-GA and MC- $\beta$ c-GA $\left(2.7 \times 10^{7}\right.$ and $5.1 \times 10^{7} M^{-1} \mathrm{~s}^{-1}$, respectively) reported by Faria et al. (2010) and the CAR acting as a singlet oxygen quencher, by a physical mechanism (step 6), MC- $\beta$ c-GA could have a greater quenching effect approximately twice that of MC-GA. Moreover at neutral $\mathrm{pH}, \mathrm{O}_{2}{ }^{--}$may generate $\mathrm{H}_{2} \mathrm{O}_{2}$ by interaction with radical species of Rf (Rf*; step 8 in Figure 5; Lu et al., 1999). In the presence of metals [e.g., $\mathrm{Fe}(\mathrm{II})], \mathrm{H}_{2} \mathrm{O}_{2}$ can produce the hydroxyl radical $\left(\mathrm{HO}^{\bullet}\right)$ by the Fenton reaction (step 9

Table 2. Trolox equivalent antioxidant capacity (TEAC) for HO ${ }^{\bullet}$ and superoxide dismutase (SOD) equivalent antioxidant activity $\left(\mathrm{EAA}_{\mathrm{SOD}}\right)$ for $\mathrm{O}_{2}{ }^{--}$with addition of microcapsules (MC) of gum arabic (MC-GA) and MC-GA with $\beta$-carotene (MC- $\beta \mathrm{c}$-GA)

\begin{tabular}{|c|c|c|}
\hline MC & $\begin{array}{l}\text { TEAC } \\
\text { for } \mathrm{HO}^{\bullet}\end{array}$ & $\begin{array}{l}\text { EAA }_{S O D} \\
\text { for } \mathrm{O}_{2}^{-}\end{array}$ \\
\hline MC- $\beta c-G A$ & $0.52 \pm 0.06$ & $0.11 \pm 0.02$ \\
\hline MC-GA & $0.30 \pm 0.05$ & $0.07 \pm 0.01$ \\
\hline
\end{tabular}
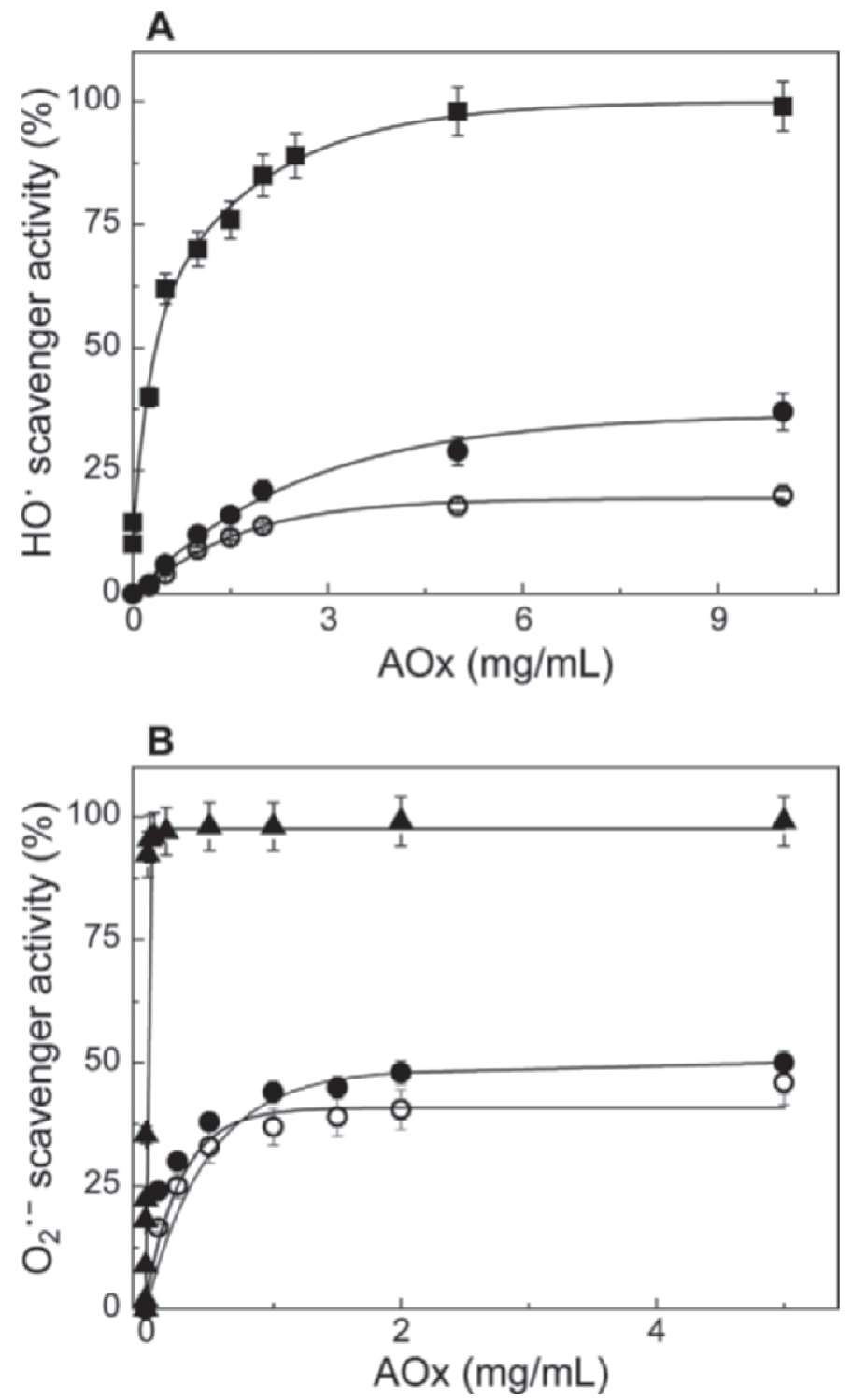

Figure 4. Percentage scavenging activity of radicals $\mathrm{HO}^{\bullet}(\mathrm{A})$ and $\mathrm{O}_{2}{ }^{\bullet-}$ (B) by microcapsules (MC) of gum arabic (MC-GA) and MC-GA with $\beta$-carotene (MC- $\beta$ c-GA). O = MC-GA; $\bullet=$ MC- $\beta$ c-GA; $\mathbf{\square}=$ Trolox (TX); $\boldsymbol{\Delta}=$ superoxide dismutase (SOD); $\mathrm{AOx}=$ antioxidant molecules. Error bars represent the SD calculated in triplicate experiments.

in Figure 5; Sutton and Winterbourn, 1989). Finally, the $\mathrm{ROS} \mathrm{O}_{2}{ }^{--}$and $\mathrm{HO}^{\bullet}$ may react with electron donor molecules (as MC) through steps 9 and 10 in Figure 5 . In the in vitro assays performed in buffer solution in the current work, the MC at the concentrations in which they were added to the milk showed moderate ability to deactivate both oxygen radicals $\left(\mathrm{O}_{2}{ }^{--}\right.$and $\mathrm{HO}^{\bullet}$ ), being 3 times more effective against $\mathrm{O}_{2}{ }^{--}$and MC- $\beta c-G A$ being more efficient than MC-GA. 


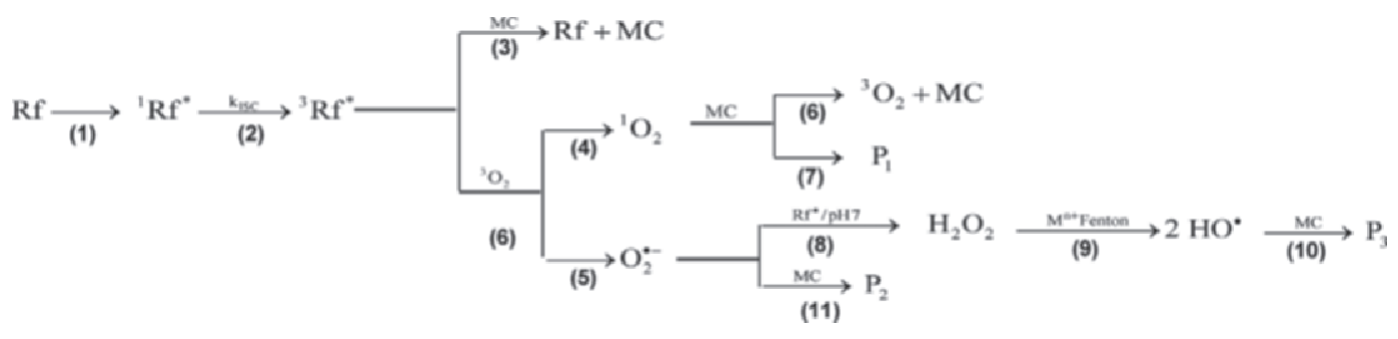

Figure 5. Possible riboflavin (Rf) photooxidation and photoprotection mechanisms in milk. ${ }^{1} \mathrm{Rf}{ }^{*}=$ electronically excited singlet state of Rf; ${ }^{3} \mathrm{Rf}^{*}=$ electronically excited triplet state of $\mathrm{Rf} ; \mathrm{k}_{\mathrm{ISC}}=$ rate constant of intersystem crossing; $\mathrm{MC}=$ microcapsule; $\mathrm{P}_{1}=$ oxidation product $1 ; \mathrm{P}_{2}$ $=$ oxidation product $2 ; \mathrm{P}_{3}=$ oxidation product $3 ; \mathrm{Rf}^{*}=$ riboflavin radical; $\mathrm{M}^{\mathrm{n}+}=$ transition metal. Steps 1 through 10 are described in the text.

\section{CONCLUSIONS}

Both MC- $\beta c-G A$ and MC-GA can act as efficient protectors of the self-photoinduced degradation of Rf. This protective effect can be explained mainly by the capability of GA to quench the ${ }^{3} \mathrm{Rf}^{*}$, avoiding the subsequent reactions of the triplet state of the flavin with molecular oxygen to produce different ROS. The deactivation mechanism of ${ }^{3} \mathrm{Rf}^{*}$ is associated with its interaction with solvent-exposed amino acid residues of the proteinaceous moiety of GA. Furthermore, the MC showed interesting scavenging properties, also associated with the complex nature of GA. The encapsulation of $\beta c$ improved the ROS scavenging properties of the MC, probably by easier accessibility of the photogenerated ROS to the localization site of $\beta \mathrm{c}$ in the MC. Altogether, the results indicate that GA-based MC containing $\mathrm{CAR}$ are efficient antioxidants to preserve milk from the deleterious effect of Rf sensitization by ambient blue light, extending its nutritional value under illuminated conditions.

\section{ACKNOWLEDGMENTS}

We thank A. Z. Mercadante [Universidade Estadual de Campinas (Unicamp), Campinas, SP, Brazil] for providing us the GA microcapsules. This work was supported in part by the Consejo Nacional de Investigaciones Científicas y Técnicas de Argentina (Buenos Aires, Argentina; CONICET-Grant PIP 2012-0374), Agencia de Promoción Científica y Tecnológica de Argentina (Buenos Aires, Argentina; ANPCyT-Grant PICTO 2009-0206 and PICT 2012-2666), and Alma Mater Studiorum-Università di Bologna (Balogna, Italy; RFO Proyecto 2010 de Italia). M. L. Boiero and N. V. Braber thank CONICET for doctoral research fellowships; C. D. Borsarelli, N. A. García, and M. A. Montenegro are research members of CONICET.

\section{REFERENCES}

Al-Majed, A. A., A. R. Abd-Allah, A. C. Al-Rikabi, O. A. Al-Shabanah, and A. M. Mostafa. 2003. Effect of oral administration of ara- bic gum on cisplatin-induced nephrotoxicity in rats. J. Biochem. Mol. Toxicol. 17:146-153.

AOAC (Association of Official Analytical Chemists). 1984. Official Methods of Analysis. 14th ed. Method 970.65. AOAC, Washington, DC.

Aruoma, O. I. 1994. Deoxyribose assay for detecting hydroxyl radicals. Methods Enzymol. 233:57-66.

Ashoor, S. H., M. J. Knox, J. R. Olsen, and D. A. Deger. 1985. Improved liquid chromatographic determination of milk and dairy products. J. Assoc. Off. Anal. Chem. 68:693-696.

Barbosa, M. I. M. J., C. D. Borsarelli, and A. Z. Mercadante. 2005. Light stability of spray-dried bixin encapsulated with different edible polysaccharide preparations. Food Res. Int. 38:989-994.

Bradley, R. L., Jr. 1980. Effect of light on alteration of nutritional value and flavor of milk: A review. J. Food Prot. 43:314-320.

Burton, G. W., and K. U. Ingold. 1984. Beta-carotene: An unusual type of lipid antioxidant. Science 224:569-573.

Bustos, R., L. Romo, K. Yáñez, G. Díaz, and C. Romo. 2003. Oxidative stability of carotenoid pigments and polyunsaturated fatty acids in microparticulate diets containing krill oil for nutrition of marine fish larvae. J. Food Eng. 56:289-293.

Cardoso, D. R., D. W. Franco, K. Olsen, M. L. Andersen, and L. H. Skibsted. 2004. Reactivity of bovine whey proteins, peptides, and amino acids toward triplet riboflavin as studied by laser flash photolysis. J. Agric. Food Chem. 52:6602-6606.

Cardoso, D. R., K. Olsen, and L. H. Skibsted. 2007. Mechanism of deactivation of triplet-excited riboflavin by ascorbate, carotenoids, and tocopherols in homogeneous and heterogeneous aqueous food model systems. J. Agric. Food Chem. 55:6285-6291.

Criado, S., S. G. Bertolotti, and N. A. García. 1996. Kinetics aspects of the rose bengal-sensitized photo-oxygenation of tryptophan alkyl esters. Ground state and photopromoted dye-tryptophan derivative interactions. J. Photochem. Photobiol. B Biol. 34:79-86.

Edge, R., D. J. McGarvey, and T. G. Truscott. 1997. The carotenoids as anti-oxidants - A review. J. Photochem. Photobiol. B 41:189 200

Faria, A. F., R. A. Mignone, M. A. Montenegro, A. Z. Mercadante, and C. D. Borsarelli. 2010. Characterization and singlet oxygen quenching capacity of spray-dried microcapsules of edible biopolymers containing antioxidant molecules. J. Agric. Food Chem. 58:8004-8011.

Gharsallaoui, A., G. Roudaut, O. Chambin, A. Voilley, and R. Saurel. 2007. Applications of spray-drying in microencapsulation of food ingredients: An overview. Food Res. Int. 40:1107-1121.

Gutteridge, J. M. C. 1981. Thiobarbituric acid-reactivity following iron-dependent free radical damage to amino acids and carbohydrates. FEBS Lett. 128:343-346.

Halliwell, B., and J. M. C. Gutteridge. 1999. Free Radicals in Biology and Medicine. 3rd ed. Oxford University Press, New York, NY.

Heelis, P. F. 1982. The photophysical and photochemical properties of flavins (isoalloxazines). Chem. Soc. Rev. 11:15-39.

Huvaere, K., and L. H. Skibsted. 2009. Light-induced oxidation of tryptophan and histidine. Reactivity of aromatic $N$-heterocycles toward triplet-excited flavins. J. Am. Chem. Soc. 131:8049-8060.

Ito, A., Y. Sato, S. Kudo, S. Sato, H. Nakajima, and T. Toba. 2003 The screening of hydrogen peroxide-producing lactic acid bacteria 
and their application to inactivating psychrotrophic food-borne pathogens. Curr Microbiol. 47:231-236.

Kristensen, D., R. V. Hedegaard, J. H. Nielsen, and L. H. Skibsted. 2004. Oxidative stability of buttermilk as influenced by the fatty acid composition of cows' milk manipulated by diet. J. Dairy Res. 71:46-50.

Liebler, D. C. 1993. Antioxidant reactions of carotenoids. Ann. N. Y. Acad. Sci. 691:20-31.

Lu, C.-Y., W.-F. Wang, W.-Z. Lin, Z.-H. Han, S.-D. Yao, and N.Y. Lin. 1999. Generation and photosensitization properties of the oxidized radicals of riboflavin: A laser flash photolysis study. J. Photochem. Photobiol. B 52:111-116.

Mahendran, T., P. A. Williams, G. O. Phillips, S. Al-Assaf, and T. C. Baldwin. 2008. New insights into the structural characteristics of the arabinogalactan-protein (AGP) fraction of gum arabic. J. Agric. Food Chem. 56:9269-9276.

Massad, W., S. Criado, S. Bertolotti, A. Pajares, J. Gianotti, J. P. Escalada, F. Amat-Guerri, and N. A. García. 2004. Photodegradation of the herbicide norflurazon sensitised by riboflavin. A kinetic and mechanistic study. Chemosphere 57:455-461.

Mestdagh, F., B. Kerkaert, T. Cucu, and B. De Meulenaer. 2011 Interaction between whey proteins and lipids during light-induced oxidation. Food Chem. 126:1190-1197.

Montenegro, M. A., I. L. Nunes, A. Z. Mercadante, and C. D. Borsarelli. 2007. Photoprotection of vitamins in skimmed milk by an aqueous soluble lycopene-gum arabic microcapsule. J. Agric. Food Chem. 55:323-329.

Mortensen, A., L. H. Skibsted, and T. G. Truscott. 2001. The interaction of dietary carotenoids with radical species. Arch. Biochem. Biophys. 385:13-19.

Mortensen, G., J. Sørensen, and H. Stapelfeldt. 2003. Effect on the modified atmosphere packaging and storage conditions on photooxidation of sliced Havarti cheese. Eur. Food Res. Technol 216:57-62.
Muñoz, A., R. Ortiz, and M. A. Murcia. 1994. Determination by HPLC of changes in riboflavin levels in milk and non-dairy imitation milk during refrigerated storage. Food Chem. 49:203-206.

Rodrigues, E., L. R. B. Mariutti, A. F. Faria, and A. Z. Mercadante. 2012. Microcapsules containing antioxidant molecules as scavengers of reactive oxygen and nitrogen species. Food Chem. 134:704-711.

Rodríguez-Huezo, M. E., R. Pedroza-Islas, L. A. Prado-Barragán, C. I. Beristain, and E. J. Vernon-Carter. 2004. Microencapsulation by spray drying of multiple emulsions containing carotenoids. J. Food Sci. 69:351-359.

Sabu, M. C., and R. Kuttan. 2002. Anti-diabetic activity of medicinal plants and its relationship with their antioxidant property. J. Ethnopharmacol. 81:155-160.

Serrano, M. P., C. D. Borsarelli, and A. H. Thomas. 2013. Type I photosensitization of $2^{\prime}$-deoxyadenosine $5^{\prime}$-monophosphate (5'-dAMP) by biopterin and its photoproduct formylpterin. Photochem. Photobiol. 89:1456-1462.

Skibsted, L.H. 2010. Understanding oxidation process in foods. Pages 3-35 in Oxidation in Foods and Beverages and Antioxidant Applications: Volume 1: Understanding Mechanisms of Oxidation and Antioxidant Activity. E. A. Decker, R. J. Elias, and D. D. McClements, ed. Woodhead Publishing, Oxford, UK.

Sutton, H. C., and C. C. Winterbourn. 1989. On the participation of higher oxidation states of iron and copper in Fenton reactions. Free Radic. Biol. Med. 6:53-60.

Trommer, H., and R. H. H. Neubert. 2005. The examination of polysaccharides as potential antioxidative compounds for topical administration using a lipid model system. Int. J. Pharm. 298:153163.

Wilkinson, F., W. Helman, and A. B. Ross. 1995. Rate constants for the decay of the lowest electronically excited singlet state of molecular oxygen in solution. An expanded and revised compilation. J. Phys. Chem. Ref. Data 24:663-1021. 